\title{
Editorial
}

\section{Emerging technologies in education for innovative pedagogies and competency development}

\author{
Asad Abbas \\ Tecnológico de Monterrey, Monterrey, Mexico \\ Samira Hosseini \\ Tecnológico de Monterrey, Monterrey, Mexico \\ José Luis Martín Núñez \\ Universidad Politécnica de Madrid, Madrid, Spain \\ Susana Sastre-Merino \\ Universidad Politécnica de Madrid, Madrid, Spain
}

\section{Introduction}

The emergent information and communication technologies (ICTs) have dramatically altered how highereducation institutions (HEIs) offer educational programs. New pedagogical approaches are born from technologies such as virtual or augmented learning platforms, hybrid classrooms, and e-learning courses (Chai et al., 2019). These technologies enabled HEIs to function in unprecedented crises including the COVID-19 pandemic, while increasing their outreach to adult learners (Abbas et al., 2021). This transition from traditional methods of instruction to a more modern style, however, can only be fruitful through policy implementations, structural changes, and shifts in educational philosophy (Bond et al., 2020; Lai \& Dower, 2019). Yet, the extent to which HEIs successfully leverage and implement these new emerging technologies and how their institutional policymaking has impacted the adaptations of ICTs has not been fully explored. Therefore, it is crucial to investigate and document how technological advancements and HEIs evolve together to provide quality education.

Technology has traditionally only been used by educators to support in- and out-of-classroom interactions of students without full integration into their education (Farjon et al., 2019). In the last two years, higher education facilitators have focused on building their digital competencies in alignment with life-changing events that occurred. Due to the COVID-19 pandemic, HEIs employed recent technologies, and viewed ICT advances well beyond that of a supporting tool for classic pedagogical methods (Sastre-Merino et al., 2021). Online learning platforms, game-based curriculum developments, distance learning, and hybrid learning have become the center point of the educational innovation projects. Online synchronized and asynchronized teaching methods have become a wide-spread alternative to on-campus classes. These were only possible through transforming and modernizing the educational systems based on such emergent technologies.

In the light of this pressing need to re-adapt, re-imagine, and re-adjust the educational practices to meet the needs of the students, the aim of this AJET special issue is to explore the practical and theoretical implications of the current developments in ICT, while highlighting the profound impact of COVID-19 on HEIs. Additionally, the purpose of this special issue is to provide an academic discussion around the topics of competency-based education, learning analytics, remote and hybrid lecturing, as well as innovative pedagogical techniques. Shedding light on successful implementations of new teaching models the paper in this issue and provides a road map for HEIs to establish new strategies that benefit the stakeholders.

\section{Papers in the special issue}

The special issue received a total of 67 submissions from various institutions across the world and by authors who represented a diverse range of expertise. After a thorough and rigorous review and revision process, eight papers were selected for inclusion within the special issue. The list of selected papers covers two major themes: innovative pedagogical approaches and competency development in education. 


\section{Innovative pedagogies}

Students' experiences and acceptance of emergency online learning due to COVID-19 by Marija Marković, Dragana Pavlović and Anastasija Mamutović explores the quality and efficiency of online teaching in the time of the COVID-19 pandemic from the students' perspective. A quantitative survey was completed by 211 undergraduate students from the Faculty of Philosophy at the University of Niš, Serbia and was analyzed through factor analysis. A qualitative approach was also presented, with semi-structured interviews with 61 undergraduate and master students. The results included a comparison of positive and negative aspects of online and face-to-face teaching and the most frequently encountered difficulties were highlighted by the authors. In addition, the study presents practical and educational policy implications to improve existing practices. It underscores the need for securing a suitable level of institutional and national support in the case of unforeseen emergencies for students as well as teachers. This includes a national strategy with guiding principles to apply digital tools in teaching by legislation, capacity building in ICT tools, financial funding planning, and physical infrastructure. Also, the authors' findings show that students' psychological needs must be taken into account to prevent negative effects of COVID-19 in virtual classroom settings.

Cheng-Yu Chung, Nayif Awad and I-Han Hsiao contributed to the special issue with their article titled Collaborative programming problem-solving in augmented reality: Multimodal analysis of effectiveness and group collaboration. The authors explored how Augmented Reality (AR) affects collaborative problem-solving in programming tasks. The participants in the study were 12 pairs of undergraduate students of introductory informatics in Arizona State University, USA. Task performance, verbal communication, and user experience were evaluated, both when using and not using AR images to complete the computer programming tasks. The findings demonstrate higher task performance, increased engagement, better attitude, and more insightful communication with the AR experience. Challenges and implications for incorporating AR when doing collaborative tasks were also discussed in this article.

Physical therapy using robotics: A project-based learning experience for undergraduate students by Edgar Lopez-Caudana, Christian Fernando Lopez-Orozco, Cesar Mendoza Bárbara, Germán Eduardo Baltazar Reyes, J. Enrique Chong-Quero and Pedro Ponce presents a study of the use of NAO robots to solve reallife problems through project-based learning. The study includes eight undergraduate engineering students from Tecnologico de Monterrey in Mexico who took part in a social service program at a rehabilitation institute to design a physical therapy routine, as well as five members of the medical staff who supported them throughout the process. The usability of the robotic platform was measured, and findings pointed out promising results on students' and users' satisfaction. Data reveal that there is a significant level of perceived usability and social influence according to the students' perspective. The real-case, provided by this project-based learning educational proposal, does not only challenge them in terms of the topics learned in class but also on the need to help people and have social impact. Beyond technical skills, social skills were also developed such as critical thinking and empathy. These improvements lead students to get more prepared to become professionals who seek the benefits of their surroundings.

Gamification during Covid-19: Promoting active learning and motivation in higher education by Elvira G. Rincon-Flores and Brenda N. Santos-Guevara introduces gamification in online classes for increased motivation and enhanced learning outcomes during the COVID-19 pandemic. The authors used a rewardbased system to improve active learning, motivation, and performance among the users. Two undergraduate courses that included 57 students at Tecnologico de Monterrey, Mexico have undertaken the gamified online course. In this study, a mixed and correlational methodological approach was used, where the qualitative results complemented the quantitative outcomes. Findings revealed that motivation, active participation, and performance increased in the online environment due to the applied gamified features and rewarding system. Moreover, recognition in a reward-based learning environment has improved the participants' emotional well-being, reducing their anxiety and sense of isolation, which have subsequently led to increased engagement.

\section{Competency development}

Sergio Tirado-Olivares, Ramón Cózar-Gutiérrez, Rebeca García-Olivares and José Antonio GonzálezCalero coauthored the article titled Active learning in history teaching in higher education: The effect of inquiry-based learning and a student response system-based formative assessment in teacher training. The 
authors presented a quasi-experimental study which focused on evaluating eventual differences in the learning scores of pre-service teachers depending on gender and the type of learning methodology (traditional lecture-based teaching compared with active inquiry-based learning methodology). Also, the predictive potential of student response system-based formative assessment on the academic achievement of university students related to gender was assessed. A control and an experimental group were randomly selected within 240 prospective primary teachers in a history class at University of Castilla-La Mancha, Spain. The findings have shown higher academic results when using inquiry-based learning compared to lecture-based teaching. Additionally, it was found that the students' scores achieved by the SRS can predict the male students' scores in a final exam, but not the female students' scores. The authors attributed these results to less interest and confidence of females in the use of ICTs compared to males.

Students' competencies discovery and assessment using learning analytics and semantic web by Khaled Halimi and Hassina Seridi-Bouchelaghem adopted a competency-based assessment approach that is supported by technology-enhanced learning systems. The study was conducted within an experimental set up with a sample of twelve computer science students at Guelma University, Algeria in the academic year 2019-2020, who were registered on a Social-based Learning Environment used to perform the experiment. Students were asked to carry out a pedagogical scenario regarding general concepts about computing. The authors proposed and analyzed a model for the use of assessment semantic analytics to discover and assess students' explicit and latent competencies through the analysis of their recorded actions and activities on the online learning system based on semantic and social web technologies. The model was also assessed by comparing the system's results and the teacher evaluation of students' competencies. The authors claimed that the proposed approach was efficient in modelling and evaluating students' competencies and can therefore enhance the design of students' competencies evaluation systems by using text mining techniques and ontological models. The authors further propose that "Assessment Analytics" should be added to the field to provide insights and profound learning on the topic.

Applying natural language processing to automatically assess student conceptual understanding from textual responses by Rick Somers, Samuel Cunningham-Nelson and Wageeh Boles investigated the application of natural language processing techniques in an educational context to evaluate their usefulness for automated assessment of students' conceptual understanding from textual responses. The study was performed at Queensland University of Technology, Australia. Students' responses to six adapted concept inventory questions were collected from a second-year undergraduate signal analysis course, between 2015 and 2020. Advantages for the formative assessment including time savings due to automated and ondemand feedback for students and educators were highlighted. Free text validity of students' justification and the confidence in their responses were modelled with four machine learning algorithms. The models performed rather well, even for small sample size, hence their applicability to the classroom was found promising.

Silvia Lizett Olivares Olivares, Mildred Lopez, Roman Martinez, Juan Pablo Nigenda Alvarez and Jorge E. Valdez-García participate in this special issue with their article titled: Faculty readiness for a digital education model: A self-assessment from health sciences educators. The study assessed the state of the preparedness of staff in a health science faculty for an unprecedented switch to remote teaching and learning using digital education model imposed by the COVID-19 pandemic. Through a web-based survey, 497 professors from the School of Medicine and Health Sciences from Tecnológico de Monterrey in Mexico self-assessed and ranked their digital competences based on the digital education model. The higher scores were achieved for active learning and web conference digital skills, while the evaluation found that faculty required further support to incorporate a full transition into online learning.

\section{Concluding remarks}

The impact of educational technology in the teaching and learning processes is a field that needs continual research. The COVID-19 pandemic has caused a series of abrupt changes in the teaching and learning processes that required incorporating technologies into the classroom. This transformative time has proven necessary to identify the opportunities that technological advances offer and select the best practices for their implementation. In this special issue, a number of studies are presented that focus on the positive (or possibly negative) effects of technology on the development and evaluation of competencies. Several methodologies are recommended as suitable approaches for HEIs, where technological trends, such as automated monitoring contribute to improved results. However, the role of professor remains essential and 
difficult to automate. Emerging technologies, such as Augmented Reality (AR) and Artificial Intelligence (AI), are granting revolutionary results to many sectors, and the educational domain is no exception (Martín-Nuñez \& Lantada, 2020). The combination of these emerging technologies with innovative pedagogical techniques allows the personalization or gamification of learning and establishes a framework with promising prospects. Technological developments drive changes in society and contribute to its evolution in a profound manner. As an ever-changing and evolving field, it is challenging to predict what roles the technological advancements will play in the future of higher education. However, the adoption and integration of emerging technologies in education provides an opportunity for HEIs to introduce novel and innovative pedagogical strategies to improve their existing educational structure, as well as to prepare both instructors and students to grow and compete in an increasingly digital world.

\section{Acknowledgements}

We are thankful to the authors who have submitted their work to this special issue and equally grateful to the reviewers from various parts of the world who have voluntarily dedicated their time to providing valuable feedback to the authors. Lastly, we are thankful to AJET Lead Editorial Team, specially to Associate Professor Jason M. Lodge for his genuine support throughout the process.

\section{References}

Abbas, A., Hosseini, S., Escamilla, J., \& Pego, L. (2021). Analyzing the emotions of students' parents at higher education level throughout the COVID-19 pandemic: An empirical study based on demographic viewpoints. Proceedings of the 2021 IEEE Global Engineering Education Conference (EDUCON), 21-23 April 2021, Vienna, Austria (pp. 857-860). IEEE. https://doi.org/10.1109/educon46332.2021.9454041

Chai, C. S., Hwee Ling Koh, J., \& Teo, Y. H. (2019). Enhancing and modeling teachers' design beliefs and efficacy of technological pedagogical content knowledge for 21 st century quality learning. Journal of Educational Computing Research, 57(2), 360-384. https://doi.org/10.1177/0735633117752453

Chung, C-Y., Awad, N., \& Hsiao, I-H. (2021). Collaborative programming problem-solving in augmented reality: Multimodal analysis of effectiveness and group collaboration. Australasian Journal of Educational Technology, 37(5), 17-31. https://doi.org/10.14742/ajet.7059

Bond, M., Buntins, K., Bedenlier, S., Zawacki-Richter, O., \& Kerres, M. (2020). Mapping research in student engagement and educational technology in higher education: A systematic evidence map. International Journal of Educational Technology in Higher Education, 17(1), 1-30. https://doi.org/10.1186/s41239-019-0176-8

Farjon, D., Smits, A., \& Voogt, J. (2019). Technology integration of pre-service teachers explained by attitudes and beliefs, competency, access, and experience. Computers \& Education, 130, 81-93. https://doi.org/10.1016/j.compedu.2018.11.010

Halimi, K., \& Seridi-Bouchelaghem, H. (2021). Students' competencies discovery and assessment using learning analytics and semantic web. Australasian Journal of Educational Technology, 37(5), 7797. https://doi.org/10.14742/ajet.7116

Lai, J. W., \& Bower, M. (2019). How is the use of technology in education evaluated? A systematic review. Computers \& Education, 133, 27-42. https://doi.org/10.1016/j.compedu.2019.01.010

Lopez-Caudana, E., Lopez-Orozco, C. F., Mendoza, C., Reyes, G. E. B., Ponce, P, \& Chong-Quero, J. E. (2021). Physical therapy using robotics: A project-based learning experience for undergraduate students. Australasian Journal of Educational Technology, 37(5), 32-42. https://doi.org/10.14742/ajet.7139

Marković, M., Pavlović, D., \& Mamutović, A. (2021). Students' experiences and acceptance of emergency online learning due to COVID-19. Australasian Journal of Educational Technology, 37(5), 1-16. https://doi.org/10.14742/ajet.7138

Martín Núñez, J. L., \& Lantada, A. D. (2020). Artificial intelligence aided engineering education: State of the art, potentials and challenges. International Journal of Engineering Education, 36(6), 17401751.

Olivares Olivares, S. L., Lopez, M., Martinez, R., Nigenda Alvarez, J. P., \& Valdez-García, J. E. (2021). Faculty readiness for a digital education model: A self-assessment from health sciences educators. Australasian Journal of Educational Technology, 37(5), 116-127. https://doi.org/10.14742/ajet.7105 
Rincon-Flores, E. G., \& Santos-Guevara, B. N. (2021). Gamification during Covid-19: Promoting active learning and motivation in higher education. Australasian Journal of Educational Technology, 37(5), 43-60. https://doi.org/10.14742/ajet.7157

Sastre-Merino, S., Nuñez-del-Río, C., Caravantes, A., \& Bravo-Ramos, J. L. (2021). Perceptions of engineering faculty members of online teaching due to COVID-19. International Journal of Engineering Education, 37(6), 1-15.

Somers, R., Cunningham-Nelson, S., \& Boles, W. (2021). Applying natural language processing to automatically assess student conceptual understanding from textual responses. Australasian Journal of Educational Technology, 37(5), 98-115. https://doi.org/10.14742/ajet.7121

Tirado-Olivares, S., Cózar-Gutiérrez, R., García-Olivares, R., \& González-Calero, J. A. (2021). Active learning in history teaching in higher education: The effect of inquiry-based learning and a student response system-based formative assessment in teacher training. Australasian Journal of Educational Technology, 37(5), 61-76. https://doi.org/10.14742/ajet.7087

Corresponding author: Asad Abbas, asad.abbas@tec.mx

Copyright: Articles published in the Australasian Journal of Educational Technology (AJET) are available under Creative Commons Attribution Non-Commercial No Derivatives Licence (CC BY-NC-ND 4.0). Authors retain copyright in their work and grant AJET right of first publication under CC BY-NC-ND 4.0.

Please cite as: Abbas, A., Hosseini, S., Martín Núñez, J. L., \& Sastre-Merino, S. (2021). Emerging technologies in education for innovative pedagogies and competency development. Australasian Journal of Educational Technology, 37(5), 1-5. https://doi.org/10.14742/ajet.7680 